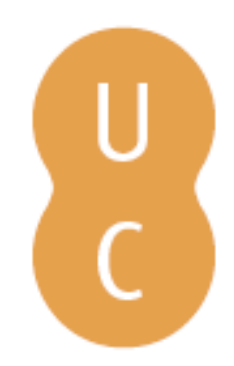

\title{
nombalina
}

\section{Hammu-rabi e o início da sua ascensão até à hegemonia: a ordem política e a legitimação divina}

\author{
Autor(es): $\quad$ Rosa, Maria de Fátima \\ Publicado por: Imprensa da Universidade de Coimbra \\ URL \\ persistente: URI:http://hdl.handle.net/10316.2/45213 \\ DOI: $\quad$ DOI:https://doi.org/10.14195/978-989-26-1626-1_4 \\ Accessed : $\quad$ 26-Apr-2023 13:59:40
}

A navegação consulta e descarregamento dos títulos inseridos nas Bibliotecas Digitais UC Digitalis, UC Pombalina e UC Impactum, pressupõem a aceitação plena e sem reservas dos Termos e Condições de Uso destas Bibliotecas Digitais, disponíveis em https://digitalis.uc.pt/pt-pt/termos.

Conforme exposto nos referidos Termos e Condições de Uso, o descarregamento de títulos de acesso restrito requer uma licença válida de autorização devendo o utilizador aceder ao(s) documento(s) a partir de um endereço de IP da instituição detentora da supramencionada licença.

Ao utilizador é apenas permitido o descarregamento para uso pessoal, pelo que o emprego do(s) título(s) descarregado(s) para outro fim, designadamente comercial, carece de autorização do respetivo autor ou editor da obra.

Na medida em que todas as obras da UC Digitalis se encontram protegidas pelo Código do Direito de Autor e Direitos Conexos e demais legislação aplicável, toda a cópia, parcial ou total, deste documento, nos casos em que é legalmente admitida, deverá conter ou fazer-se acompanhar por este aviso.

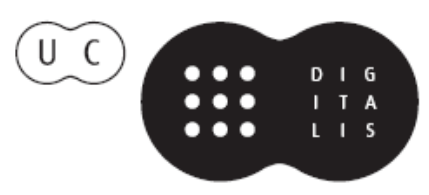




\section{Arqueologias de Império}

\section{Delfim Leão, José Augusto Ramos, Nuno Simões Rodrigues (coords.)}

IMPRENSA DA UNIVERSIDADE DE COIMBRA 


\title{
HAMMU-RABI E O INÍCIO DA SUA ASCENSÃo ATÉ À HEGEMONIA: A ORDEM POLÍTICA E A LEGITIMAÇÃo DIVINA ${ }^{1}$ (Hammu-rabi and the beginning of his hegemonic ascent: political order and divine legitimation)
}

\author{
MARIA DE Fátima Rosa \\ (frosa@fcsh.unl.pt; ORCID: 0000-0003-2302-7751)
}

Universidade Nova de Lisboa, CHAM; Universidade dos Açores

Resumo - Este estudo pretende analisar a ideologia subjacente às políticas sociais e militares levadas a cabo por Hammu-rabi em dois momentos cruciais da história da Babilónia. Estes dois episódios, a guerra contra o Elam e o ataque ao reino de Larsa, constituem o ponto de viragem do reinado de Hammu-rabi e marcam o início da sua ascensão até à hegemonia.

Palavras-Chave: Babilónia; Hammu-rabi; Larsa; Elam; Hegemonia.

AвstraCt - This brief study intends to analyze the ideology underlying the social and military policies carried out by Hammu-rabi at two crucial moments in the history of Babylon. These two episodes, the war against Elam and the attack against the kingdom of Larsa, constitute a turning point in the reign of Hammu-rabi and highlight the beginning of his hegemonic ascent.

Keywords: Babilonia; Hammu-rabi; Larsa; Elam; Hegemony.

Este breve estudo pretende analisar a ideologia subjacente às políticas sociais e militares levadas a cabo por Hammu-rabi em dois momentos cruciais da história da Babilónia. Estes dois episódios, a guerra contra o Elam e o ataque ao reino de Larsa, constituem o ponto de viragem do reinado de Hammu-rabi e marcam o início da sua ascensão até à hegemonia.

Alguns autores consideram que, no seu apogeu, o território governado por Hammu-rabi constituía um verdadeiro «império»². O período inaugurado pelo monarca, em cerca de 1763 a.C. ${ }^{3}$, seria marcado pela preponderância da Babilónia e viria a terminar apenas em 1595 a.C., com a tomada da cidade pelos hititas.

\footnotetext{
${ }^{1}$ Abreviaturas usadas: $A b B$ - Altbabylonische Briefe; ARM - Archives Royales de Mari; CH - «Código» de Hammu-rabi; LAPO - Littératures anciennes du Proche-Orient; RA - Revue d'Assyriologie et d'Archéologie Orientale; RIME - The Royal Inscriptions of Mesopotamia, Early Periods.

${ }^{2}$ Veja-se Charpin 2003, 105-6. O autor considera que, segundo os critérios que geralmente definem um império, isto é, a diversidade etnolinguística, a extensão territorial e o exercício de um poder forte e centralizado, é possível designar a Babilónia do final do reinado de Hammu-rabi como império.

${ }^{3}$ Data da anexação de Larsa.
} 


\section{OS PRIMEIROS ANOS DE REINADO}

Hammu-rabi pertencia a uma das várias dinastias amorritas que se haviam instalado na bacia mesopotâmica. Quando o soberano subiu ao poder, em 1792 a.C., a Babilónia tinha pouco mais de um século e cobria uma extensão territorial pouco significativa comparativamente às grandes potências da altura ${ }^{4}$.

As fontes de que dispomos para estudar o início do reinado de Hammu-rabi são muito escassas ${ }^{5}$. A julgar pela designação atribuída aos primeiros anos do seu governo, Hammu-rabi teria feito algumas incursões em territórios vizinhos. De entre estas ações militares, destacam-se a tomada de Isin e Uruk (no $7^{\circ}$ ano do reinado) e a conquista do Malgiûm (no $10^{\circ}$ ano do reinado). Contudo, o facto de vermos estes territórios retomarem a sua anterior suserania ${ }^{6}$ ou reconquistarem a sua independência ${ }^{7}$, indica-nos que constituíram ações pontuais, sem grandes efeitos práticos e pouco vocacionadas para uma verdadeira ambição expansionista.

A conjuntura política de então, marcada até 1775 a.C. pelo domínio de Samsî-Addu, soberano do reino da Alta Mesopotâmia, e a posição geográfica da Babilónia, localizada entre as potências de Larsa e de Ešnunna, terão constituído entraves a uma possível expansão. Hammu-rabi terá, por conseguinte, concentrado os seus esforços no desenvolvimento interno, promovendo a coesão, criando infraestruturas e, sobretudo, consolidando a sua relação com o mundo divino. Na designação atribuída aos anos do seu reinado, são várias as referências à construção de templos e às doações de tronos e de estátuas aos deuses.

\section{OS ANOS DAS GRANDES CONVULSÕES}

A morte de Samsî-Addu, em 1775 a.C., inicia um período de relativo equilíbrio entre as várias potências do mundo siro-mesopotâmico. Após alguns anos,

${ }^{4}$ Cf. Ibid. 44.

${ }^{5}$ De entre estas, destacam-se algumas inscrições reais e documentos de arquivos privados. Para além destes textos, a designação dos anos do reinado de Hammu-rabi é um elemento importante que nos permite conhecer os principais acontecimentos políticos, militares ou religiosos. A partir de 1775 a.C., as fontes que testemunham com maior rigor as políticas diplomáticas de Hammu-rabi provêm do palácio real de Zimrî-Lîm. Os Arquivos Reais de Mari (ARM) abrangem o período em que se desenrolam as principais guerras na bacia da Mesopotâmia e terminam no ano de 1762 a.C., precisamente quando a cidade é tomada por Hammu-rabi. No que respeita à administração interna, destaca-se a correspondência trocada entre Hammu-rabi e os seus altos funcionários, Šamaš-hașir e Sîn-iddinam. Esta documentação retrata o período consequente à anexação do reino de Larsa e as medidas tomadas para proceder à sua integração no território babilónico.

${ }^{6}$ As cidades de Isin e de Uruk estavam, no início, na posse de Larsa. O soberano Rîm-Sîn teria reconquistado as possessões pouco tempo após a tomada de Hammu-rabi.

${ }^{7} \mathrm{O}$ Malgiûm dominava um sector importante do rio Tigre e controlava o fornecimento de água a Larsa. Tal como se passou relativamente às possessões de Isin e de Uruk, também o reino do Malgiûm se teria libertado pouco tempo depois do jugo de Hammu-rabi. 
a situação começa a tornar-se cada vez mais propícia a possíveis ambições expansionistas. No entanto, caso Hammu-rabi alimentasse algumas esperanças de expansão territorial, as mesmas ver-se-iam comprometidas após a entrada em cena de um poder político que até então se mantivera à margem dos problemas da Mesopotâmia: o Elam. De facto, quando em 1765 a.C. ${ }^{8}$ o sukkal ${ }^{9}$ do Elam $^{10}$ decide atacar o reino de Ešnunna, Hammu-rabi coloca-se a seu lado, enviando os seus contingentes para ajudar na conquista da cidade. O que o soberano certamente não esperava era que, após a vitória, o sukkal se instalasse no trono dessa cidade. Ora, a razão principal pela qual Hammu-rabi o auxiliara devera-se ao facto de pretender retomar as antigas cidades de Mankisum e Upi. Estas possessões teriam pertencido à Babilónia no reinado do seu avô, Apil-Sîn, antes de caírem nas mãos do rei de Ešnunna.

A presença do sukkal em território mesopotâmico impunha algumas restrições à ação política de Hammu-rabi. É que Șiwa-palar-huhpak era não só rei do Elam como também suserano de vários reinos siro-mesopotâmicos, entre os quais a Babilónia. As tensões entre ambos têm início quando o sukkal, fazendo valer a sua autoridade, endereça a Hammu-rabi uma carta exigindo a libertação das cidades recentemente reconquistadas. $\mathrm{O}$ tom autoritário com que Șiwa-palar-huhpak se lhe dirige denota o esfriar das relações entre ambos: "As cidades que deténs não são minhas? Liberta-as e submete-te ao meu jugo! Senão, pilharei o teu país» ${ }^{11}$.

A recusa de Hammu-rabi precipita a guerra, que rapidamente se espalha por todo o mundo siro-mesopotâmico. É precisamente este conflito, que atinge uma dimensão «mundial», que vai catapultar Hammu-rabi para um lugar de primeiro plano na cena política internacional e marcar o início da sua ascensão até à hegemonia.

Esta ascensão é bastante célere. Podemos dizer que no espaço de escassos quatro anos o rei da Babilónia se consegue afirmar como o soberano mais poderoso da Mesopotâmia. Um aspeto que nos possibilita compreender o impacto das suas conquistas durante este período é precisamente a titulatura que ele vai adotando. Ora, aquando da derrota do Elam, no $30^{\circ}$ ano do seu reinado,

${ }^{8}$ A data da queda de Ešnunna não é consensual. Em Charpin e Ziegler 2003, 248, Dominique Charpin considera que a derrota do reino de Ibâl-pî-El II data de 1765 a.C. Todavia, a intensidade do intercâmbio de presentes entre o sukkal e alguns monarcas sírios nos dois anos precedentes poderá ser testemunho de que a mesma terá ocorrido numa data anterior. De facto, este intercâmbio poderá ter sucedido a tomada da cidade e o reforço das relações entre os aliados.

${ }^{9}$ sukkal ou sukkalmah é o título do governador do Elam.

${ }^{10} \mathrm{O}$ reino do Elam localizava-se na parte ocidental do atual Irão, nos montes Zagros, localizados a este da Mesopotâmia. O forte poder do Elam representava uma ameaça constante para a Mesopotâmia.

${ }^{11}$ A.3618, 1. 21'-24' (texto editado em Charpin 1999, 122, n. 37). 
Hammu-rabi era simplesmente conhecido como o «rei da Babilónia». A este título, ele vai adicionando sucessivamente:

- O título de «rei do país de Sumer e Akkad», após a anexação do reino de Larsa, que tem lugar no $31^{\text {a }}$ ano do reinado;

- O título de «rei de todo o país amorrita», após a derrota do reino de Mari ${ }^{12}$, que tem lugar no $32^{\mathrm{a}}$ ano do seu reinado;

- O título de «rei dos quatro cantos do mundo» (isto é, do «universo»), que o soberano adota a dada altura do seu reinado e que é aquele que melhor expressa as suas pretensões hegemónicas e «universais»" ${ }^{13}$.

Resta-nos referir que entre a anexação do reino de Larsa e a destruição de Mari $^{14}$ Hammu-rabi se apodera da cidade de Ešnunna ${ }^{15}$, anulando assim os dois poderes que teriam, no início, constituído entraves à sua expansão: Larsa e Ešnunna.

\subsection{A derrota do Elam}

$\mathrm{O}$ ataque do sukkal do Elam não se teria limitado à Babilónia. Outros estados foram afetados pela ofensiva elamita, nomeadamente os pequenos reinos da região da Jazira ${ }^{16}$. Estes países estavam unidos por laços de aliança aos poderosos reinos siro-mesopotâmicos. O soberano de Mari, por exemplo, teria desde cedo imposto uma poderosa rede de aliados (de vassalos) na região do delta do rio Habur. Como suserano, competia-lhe prestar apoio militar aos seus vassalos. O próprio rei de Mari, Zimrî-Lîm, seria, por sua vez, um «servo» do rei do Yamhad, um importante centro de poder a oeste da Síria. Ora, esta complexa teia de relações diplomáticas, obrigava a que, em caso de guerra, todos aqueles que tinham contraído uma aliança, enviassem os seus contingentes militares para prestar auxílio aos seus aliados. Assim, aquando do início do conflito, tanto Hammu-rabi como os monarcas da região da Jazira recorreram às suas várias alianças na esperança de obterem apoio militar. Compreendemos então o porquê desta guerra se ter espalhado tão depressa por todo o Próximo Oriente.

${ }^{12} \mathrm{O}$ reino de Mari, que controlava todo o sector do médio Eufrates, caracterizava-se pelo seu forte dimorfismo social. Um dos aspetos que marca o reinado de Zimrî-Lîm é a luta constante pela coesão social e pela pacificação interna. As grandes tribos amorritas de então, os bensimalitas e os benjaminitas, teriam exercido um papel determinante no desenvolvimento interno e na política externa do reino. Após a queda de Larsa e de Ešnunna, Mari passou a constituir o último grande reino amorrita que faltava a Hammu-rabi conquistar para se poder declarar rei do país de Amurru.

${ }^{13}$ Veja-se RIME 343, 1. 1-5 e 348, 1. 4.

${ }^{14}$ A conquista ocorre em 1762 a.C., no $31^{\circ}$ ano do reinado de Hammu-rabi.

${ }^{15}$ Ešnunna reconquista a sua independência após a derrota do Elam pelas forças aliadas de Hammu-rabi. A população do reino elege então como rei um general chamado Șillî-Sîn. As relações entre o novo soberano de Ešnunna e Hammu-rabi são de início amigáveis. No entanto, divergências políticas terão levado a um distanciamento.

${ }^{16}$ Região localizada no Norte, entre os rios Eufrates e Tigre. 
O Elam viria a ser derrotado cerca de um ano após os primeiros confrontos. $\mathrm{O}$ facto de a batalha mais importante se ter desenrolado em território babilónico, mais precisamente na cidade de Hîrîtum, contribuiu para que Hammu-rabi saísse desta guerra «pan-amorrita» como o grande vencedor. Em grande parte, podemos dizer que os esforços de união das tropas e de apelo à ação partiram do próprio Hammu-rabi. É ele quem incita o seu homólogo Zimrî-Lîm a escrever-lhe constantemente de modo a possibilitar uma ação conjunta que pudesse travar a incursão do $\mathrm{Elam}^{17}$. É ele também quem exerce pressão junto dos seus aliados ${ }^{18}$ para que os seus contingentes militares se reúnam e ponham fim à guerra. Não obstante, como lugar-tenente da sua divindade e devoto do mundo divino, Hammu-rabi é o primeiro a reconhecer que a tão almejada vitória só fora possível «com o poder supremo dos grandes deuses» ${ }^{19}$.

De facto, neste episódio transparece uma ideologia de guerra muito clara, segundo a qual o soberano agia segundo a ordem divina, ou seja, defendendo o interesse dos deuses. Não só a vitória lhes é atribuída, como também a própria razão pela qual Hammu-rabi se envolvera na guerra. Uma vez que se tratara de um ataque, o rei babilónico vira-se obrigado a defender o seu território. Todavia, ele só o fizera após Enlil descortinar os desígnios do elamita. Com efeito, é do seguinte modo que se expõe o motivo da guerra a um grupo de mensageiros elamitas:

«O vosso senhor (sukkal do Elam) transgrediu o limite do juramento dos seus deuses e tenciona pecar e agir com inimizade. Que ele venha e que Enlil veja o «sim» e o «não» do seu coração (= as suas intenções)» ${ }^{20}$.

O que sobressai nesta exposição é precisamente o facto do sukkal do Elam ter sido primeiramente sujeito a um «exame» por parte de Enlil. O deus tê-lo-ia posto à prova após a transgressão da vontade divina, isto é, do seu juramento. Hammu-rabi era ainda um ator passivo nesta contenda. O mesmo só teria agido

${ }^{17}$ É no Norte (na região de influência do rei de Mari) que a ameaça do Elam tem mais impacto. Zimrî-Lîm encontrava-se em viagem pelo Oeste quando tiveram início os conflitos na Mesopotâmia. Os documentos ARM VI 51 e 52 e $A R M$ XXVIII 7, 8 e 9 testemunham esta ausência de Zimrî-Lîm e atestam a frequência com que Hammu-rabi fazia chegar informações ao seu homólogo, porventura sublinhado a urgência do seu regresso.

${ }^{18} \mathrm{Na}$ prática, quem reúne a maior parte das tropas é Zimrî-Lîm. Contudo, é Hammu-rabi quem o pressiona para a convocação dos exércitos e quem no fim recebe os louros. À Babilónia teriam chegado vários contingentes mariotas. As tropas fornecidas pelo Yamhad e pelo Zalmaqum (também por intermédio do monarca mariota) ter-se-iam deslocado para Kurdâ com a intenção de travarem a ameaça do Elam no Norte.

${ }^{19}$ Veja-se a designação atribuída ao $30^{\circ}$ ano do seu reinado: «ano em que Hammu-rabi, o rei, o poderoso, o amado de Marduk, afastou o exército do Elam com o poder dos grandes deuses (...) e consolidou as fundações de Sumer e Akkad».

${ }^{20}$ ARM XXVI/2 370, 1. 15'-17'. 
após a decisão de Enlil e a aprovação dos deuses, que lhe teriam então conferido o seu «poder supremo». Como o documento afirma, o sukkal destabilizara a ordem política e social da Babilónia e, por extensão, a própria ordem divina. Isto porque o juramento constituía o ato mais importante aquando da conclusão de uma aliança. Era este passo que selava a união entre os dois contraentes, ao inscrever a ordem dos respetivos reinos na própria ordem celeste.

Questionamo-nos acerca desta referência a Enlil. Tratando-se de um deus supremo do panteão sumério-acádico podemos especular se o apelo a esta divindade específica não estará relacionado com o facto de ele estar muito associado ao exercício do poder. Segundo alguns autores, a guerra terá despertado sentimentos de uma espécie de «nacionalismo» mesopotâmico ${ }^{21}$. Como referimos, o conflito ter-se-ia estendido por todo o mundo siro-mesopotâmico, ou seja, pelo mundo amorrita. Podemos dizer que pela primeira vez na Mesopotâmia encontramos indícios concretos de uma noção do «outro»: do estrangeiro ${ }^{22}$. E este foi certamente um dos aspetos que contribuiu para o prestígio de Hammu-rabi após a vitória. De facto, não é apenas a Babilónia que sai vencedora da guerra, mas todo o mundo amorrita. Hammu-rabi emerge assim como o benfeitor dos amorritas, como aquele que triunfara sobre a ameaça da instauração do caos no Próximo Oriente.

A importância do deus Enlil pode ser testemunhada no prólogo do famoso «código» de Hammu-rabi. A inscrição aí gravada inicia com a seguinte afirmação: «Quando An e Enlil atribuíram a Marduk o poder de Enlil (ellilūtum) sobre toda a população ${ }^{23}$. Ora, para que o deus tutelar da Babilónia, Marduk, pudesse governar a população do país, ter-lhe-ia sido outorgado pelos grandes deuses o ellilūtum. Este poder divino, no fundo, o poder supremo, o poder de exercer a realeza ${ }^{24}$, é bastante sintomático do lugar primordial que Enlil ocupava no panteão mesopotâmico. Como deus supremo, Enlil seria capaz de corresponder ao sentimento de identidade, ao poder e à união que Hammu-rabi esperava, porventura, obter dos deuses e dos mesopotâmios neste período inicial das hostilidades.

Por outro lado, tendo Enlil em seu poder as tabuinhas do destino ${ }^{25}$, podemos também considerar que esta referência estaria associada à sua capacidade

${ }^{21}$ Sobre este aspeto, veja-se o estudo Charpin et Durand 1991.

${ }^{22}$ Uma carta dos Arquivos Reais de Mari testemunha esta noção. Um chefe nómada dirige-se a Zimrî-Lîm, afirmando que se porventura os elamitas chegassem às margens do Eufrates facilmente se distinguiriam dos amoritas, tal como as formigas brancas se distinguiam das negras (A.3080, texto editado em Durand 1990, 104-6). Ver também LAPO 17, 733.

${ }^{23} \mathrm{CH}$, Prólogo, I, 1. 3-8 e 11-13.

${ }^{24}$ Segundo Sanmartín et López 1993, 278, a ellilūtum era a «dignidade, o poder e a posição de Enlil», sinónimo de «divindade suprema».

${ }^{25} \mathrm{Na}$ mitologia mesopotâmica, Enlil era o detentor das tabuinhas do destino, onde estavam inscritos os destinos (šimtum) de todos. 
de antever certos acontecimentos futuros, de conhecer as intenções e os destinos de todos. É pois a Enlil que se apela para que veja o «sim» e o «não», isto é, os sentimentos verdadeiros ou falsos do sukkal.

A intervenção dos deuses não se limitava ao simples ato de legitimar a guerra. Sem o apoio da divindade, muito dificilmente o rei se sagraria vencedor. Nesta ideologia, o deus não é um mero espectador do conflito. Pelo contrário, ele participa nele ativamente e é precisamente a sua presença que dita a derrota do inimigo. Assim, quando Hammu-rabi consegue afastar os exércitos elamitas da Mesopotâmia e libertar a Babilónia da sua pesada ameaça, é no mundo divino que se encontra a explicação para o sucedido. Como se recorda num documento mais tardio:

«... ele (o elamita) planeou devorar o país da Babilónia. Se o deus do meu senhor ${ }^{26}$ não tivesse aparecido, ele teria agido durante longo tempo como se a semente do país da Babilónia não tivesse sido criada.... ${ }^{27}$.

O interlocutor pretende sublinhar a mudança observada na atitude do rei de Elam após a guerra. Esta mudança devera-se à aparição do deus, que impedira o elamita de conquistar a Babilónia. É a intervenção da divindade que altera as intenções do sukkal, fazendo com que este aceite a semente (a vida) do país de Hammu-rabi.

A rejeição da existência do país da Babilónia e a tentativa da sua anulação, acusações de que Șiwa-palar-huhpak era alvo, são muito significativas do atentado que o mesmo cometia contra Hammu-rabi e contra a esfera celeste. Isto porque paralelamente à outorga do ellilütum a Marduk, os deuses «pronunciaram o nome sublime da Babilónia e atribuíram-lhe preponderância sobre os quatro cantos do mundo» ${ }^{28}$.

$\mathrm{Na}$ Mesopotâmia, "pronunciar o nome» equivalia a fixar o destino; significava atribuir uma função a alguém ou definir a natureza de uma determinada coisa. A bem-aventurança da Babilónia teria, então, sido decretada pelos deuses. O destino de Marduk, a quem havia sido dado o poder, unia-se assim ao destino da Babilónia, cidade que os deuses haviam eleito. Negar a existência do país da Babilónia significava, portanto, negar a palavra pronunciada pelos deuses. A punição do sukkal ultrapassava assim o domínio da justiça terrena, vendo-se a esfera celeste envolvida na aplicação do castigo ${ }^{29}$. Em suma, a hegemonia que

${ }^{26} \mathrm{O}$ «meu senhor» referido no texto não é Hammu-rabi mas sim um dos seus aliados que terá participado na guerra - Zimrî-Lîm. Todavia, o que aqui importa sublinhar é a importância da participação dos deuses nos destinos humanos.

${ }^{27}$ A.1931, 1. 8-11 (texto editado em Charpin 1999, 126, n. 53).

${ }^{28} \mathrm{CH}$, Prólogo, I, 1. 16-19.

${ }^{29}$ No documento ARM XXVIII 1, a desavença entre as tropas elamitas e ešnunnitas, suas aliadas, que teria, em grande parte, ditado a ruína do Elam, é descrita como partindo de uma 
Hammu-rabi viria a alcançar para a Babilónia não era senão o cumprimento da vontade divina prevista e inscrita na ordem cósmica.

O favoritismo que os deuses haviam concedido à Babilónia explicava-se também pelo facto do seu soberano ser «o piedoso, o devoto suplicante dos grandes deuses $»^{30}$. Trata-se de uma relação de complementaridade. Porque Hammu-rabi era reverente e temente aos deuses, porque ele cumpria os rituais, as divindades outorgavam-lhe poderes, engrandeciam a sua realeza e elevavam-no perante os demais. É o próprio Hammu-rabi quem o indica: «Eu sou Hammu-rabi, rei da justiça, a quem Šamaš deu a verdade (kīnātum) $»^{31}$.

O deus Šamaš, divindade solar mesopotâmica, estava muito associado aos conceitos de verdade, de justiça e de equidade. Era uma divindade na qual se projetavam as noções de ordem e os ideais que possibilitavam a manutenção da harmonia cósmica. O principal fundamento da ordem era precisamente o exercício da justiça. Como tal, Šamaš estava também muito associado à adivinhação e aos oráculos, que ditavam as normas a cumprir para alcançar esse equilíbrio. Por isso, não é de estranhar que Šamaš fosse um dos deuses mencionados aquando dos juramentos que se realizavam com o intuito de selar os acordos diplomáticos.

A ordem internacional assentava no cumprimento de acordos e tratados diplomáticos. Durante a guerra contra o Elam, Hammu-rabi precisava de garantir que as várias potências do mundo siro-mesopotâmico estavam do seu lado e que tinham um objectivo comum: a derrota dos elamitas. O soberano teria então procedido a uma série de negociações diplomáticas com vista à conclusão de alianças políticas. Ao seu homólogo mariota, Hammu-rabi prometera: «Por ele (Zimrî-Lîm), eu erguerei a minha mão para Šamaš. Far-me-ás jurar $^{32}$ diante de Šamaš» ${ }^{33}$. A importância deste juramento explica-se, como dissemos, pelo facto do futuro transgressor se tornar responsável perante as divindades. Como vimos, teria sido devido à transgressão de um juramento idêntico que o Elam sofrera o desaire imposto por Hammu-rabi. No fundo, estes acordos constituíam um meio de impor a ordem e de legitimar o poder de ação do rei em caso de traição.

Em suma, para que se conservasse a ordem política e a ordem cósmica, Hammu-rabi teria de vencer a guerra contra o Elam. Era esta a vontade dos grandes deuses. E é aqui que tem início o seu caminho até à hegemonia. $\mathrm{Na}$ verdade, as ambições hegemónicas do monarca babilónico fazem-se sentir

ação divina: «os nossos deuses instalaram a hostilidade entre o Elam e Ešnunna. Todos tiveram medo deles, mas (agora) o deus ocupa-se deles» (1. 5'-6').

${ }^{30} \mathrm{CH}$, Prólogo, IV, 1. 64-66.

${ }^{31}$ CH, Epílogo, XXV R, 1. 95-98.

${ }^{32} \mathrm{O}$ juramento é realizado na Babilónia, na presença dos embaixadores mariotas.

${ }^{33}$ A.4626, 1.8'-10' (texto editado em Charpin 1990b 111). 
logo após o final do conflito, quando o mesmo expressa a vontade de se instalar no trono de Ešnunna ${ }^{34}$, vagado após a retirada dos elamitas. No entanto, as suas expectativas sairiam goradas, uma vez que a população do reino escolheria para a sua chefia um general saído do seio do exército, de seu nome Șillî-Sîn.

\subsection{A conquista de Larsa}

Depois do contratempo em Ešnunna, Hammu-rabi decide voltar-se para o sul, para o reino de Larsa. O ataque ao seu homólogo ocorre no rescaldo da guerra contra o Elam. Para Hammu-rabi, a urgência desta ofensiva explicava-se devido à necessidade de garantir a paz da Babilónia e de impedir que a ordem do reino se diluísse. É que, segundo o mesmo, Rîm-Sîn fizera várias incursões no seu país, perturbando a sua estabilidade interna. A justificação da guerra é apresentada pelo próprio Hammu-rabi do seguinte modo: «"O homem de Larsa desrespeitou o meu país fazendo pilhagens (...) Depois de os grandes deuses terem afastado a garra do elamita deste país, eu olhei pelo bem-estar do homem de Larsa, (concedendo-lhe) numerosos favores, mas ele não me recompensou esses favores. Agora, eu queixei-me a Šamaš e a Marduk e eles responderam-me continuamente "sim". Eu não iniciei este ataque sem (o consentimento d) a divindade" $»^{35}$.

Na realidade, o ataque a Larsa devera-se não tanto a este motivo mas sim ao facto de Rîm-Sîn ter adotado uma postura algo imparcial durante a guerra contra o Elam. Hammu-rabi esperava na altura contar com o auxílio militar de Larsa. Contudo, os exércitos aliados prometidos por Rîm-Sîn nunca teriam chegado a território babilónico. Esta atitude poderá ser explicada pelo facto de Rîm-Sîn estar unido ao sukkal do Elam através de laços dinásticos.

De qualquer forma, Hammu-rabi não agira sem antes consultar os deuses. $\mathrm{O}$ ataque surge justificado pelas pilhagens operadas por Rîm-Sîn em território babilónico. A guerra era necessária para garantir a ordem política e a estabilidade. No epílogo do «código» de Hammu-rabi, encontramos uma afirmação que expressa muito bem a ideologia subjacente a estas ações militares. Hammu-rabi afirma: «devido ao poder que Marduk me concedeu, eu aniquilei os inimigos em cima e em baixo, acabei com as batalhas e providenciei o bem-estar do país» ${ }^{36}$. Como vemos, o propósito da guerra era aniquilar os inimigos, era acabar com os possíveis perturbadores da paz. A guerra não era senão um meio de permitir ao rei garantir a ordem interna.

\footnotetext{
${ }^{34}$ Veja-se o documento A.257 (= LAPO 16 300), 1. 8-10. Zimrî-Lîm expressa o seu apoio relativamente às pretensões de Hammu-rabi: «Se a população de Ešnunna te der o seu consentimento, exerce tu próprio a realeza no país de Ešnunna».

${ }^{35}$ ARM XXVI/2 385, 1. 8'-15'.

${ }^{36} \mathrm{CH}$, epílogo, XXIV R, 1. 28-34.
} 
Contudo, a guerra era também uma ação que carecia da aprovação divi$n^{37}$. Assim sendo, a ofensiva contra Larsa só teria ganho força após Šamaš e Marduk responderem constantemente "sim» às perguntas (às várias consultas oraculares) de Hammu-rabi. «Sim», o soberano tinha a aprovação dos deuses. "Sim», a guerra era necessária e justificada. Šamaš e Marduk são referidos no documento como os deuses tutelares dos dois países em confronto, o reino de Larsa e a Babilónia.

Para compreendermos melhor o papel que cabia ao soberano na guerra, recuperamos novamente a parte inicial do prólogo do «código» de Hammu-rabi:

«Quando An e Enlil atribuíram a Marduk o poder de Enlil sobre toda a população (...), (quando) pronunciaram o nome sublime da Babilónia e lhe atribuíram preponderância sobre os quatro cantos do mundo (...) Então, (...) An e Enlil pronunciaram o meu nome para assegurar o bem-estar da população ${ }^{38}$.

Assim sendo, não só o destino de Marduk estava intimamente associado ao destino da Babilónia, como ambos eram indissociáveis do próprio destino de Hammu-rabi. Se os deuses haviam decretado a supremacia da Babilónia, a Hammu-rabi, seu soberano, estava destinada a hegemonia perante os demais, a realeza dos «quatro cantos do mundo».

Concluindo, para ordenar o mundo, os grandes deuses, An e Enlil, teriam nomeado um chefe supremo: Marduk. A esta medida juntara-se a elevação da sua morada na terra, a Babilónia, e a designação de um lugar-tenente - alguém que pudesse honrar Marduk e simultaneamente desempenhar o seu papel no mundo terreno. A pessoa escolhida para assumir essa função fora Hammu-rabi. A ele, competia-lhe zelar pelo bem-estar da população, defender o território de Marduk e assegurar a paz. Era seu dever tomar as disposições necessárias de modo a responder convenientemente ao «sim» dado pela divindade.

A guerra contra Larsa terá durado mais de seis meses ${ }^{39}$. Após um prolongado cerco à capital, a notícia da vitória chegava finalmente ao soberano: «Hoje, o deus

${ }^{37}$ A intervenção da divindade na guerra tinha também como fim aplacar eventuais receios do soberano. A inquietação do monarca no momento que precede o conflito é percetível no texto $A R M X X V I / 2$ 379: «Hammu-rabi está receoso porque o inimigo pelo qual Šamaš perguntou é numeroso». Sublinhamos que Rîm-Sîn é posto à prova precisamente por Šamaš, o deus da justiça (ou seja, o deus pergunta por ele). Ora, porque Šamaš decide fazer Rîm-Sîn pagar pelas suas desonestidades e pela sua conduta traiçoeira, Hammu-rabi, na qualidade de «favorito» dos deuses, como aquele em quem recaía a tarefa de agradar a Šamaš e a Marduk, é impelido para o combate. Em última análise, é a vontade divina que o rei cumpre.

${ }^{38} \mathrm{CH}$, prólogo, I, 1. 3-8, 11-13, 27 e 45-49.

${ }^{39}$ Como indica Mieroop 1993, 63, é possível que o reino se encontrasse enfraquecido: «It is more likely that, to the contrary, the second half of Rim-Sin's reign was one of weakness, allowing Babylon to organize military incursions deep into Larsa's territory». 
do meu senhor marchou à frente das tropas do meu senhor. A lança do malfeitor e do inimigo foi quebrada. A cidade de Larsa foi tomada $\star^{40}$. Hammu-rabi torna-se então senhor de toda a zona meridional da Mesopotâmia, procedendo à integração do antigo reino de Larsa no território babilónico. Foi este o momento em que se diluiu o equilíbrio político existente até então no mundo siro-mesopotâmico. Ao conquistar o Sul e ao declarar-se senhor do país de Sumer e Akkad ${ }^{41}$, Hammu-rabi transformou-se no monarca mais poderoso da Mesopotâmia.

A reputação alcançada por Hammu-rabi é percetível nas diversas movimentações que ocorreram após a vitória. Confrontados com o poder redobrado da Babilónia, alguns monarcas decidiram prescindir de antigas alianças para se juntarem a Hammu-rabi ${ }^{42}$. Outros, como Șillî-Sîn, aproveitaram a oportunidade para concluir acordos de paz pendentes ${ }^{43}$. Começou assim a desenhar-se um novo quadro político-diplomático e a estabelecer-se uma conjuntura política favorável à ascensão do soberano da Babilónia.

\section{A CONSOLIDAÇÃo DO REINO}

Ao mesmo tempo que prossegue o seu percurso político e militar, conquistando Ešnunna, destruindo Mari e, já no final do reinado, tomando Ashur e a zona do Šubartum, Hammu-rabi procede à gestão e consolidação do seu território. Um aspeto importante neste esforço de consolidação é a integração do território do antigo reino de Larsa na Babilónia.

O estabelecimento da ordem política no território recentemente conquistado ter-se-ia operado em duas vertentes diferentes. Porque Šamaš havia concedido a «verdade» a Hammu-rabi, competia-lhe exercer a justiça sobre a população. O próprio o afirma:

«(eu sou) o sol da Babilónia, aquele que faz aparecer a luz sobre o país de Sumer e Akkad, o rei que impõe obediência aos quatro cantos do mundo (...) Quando Marduk me encarregou de impor a ordem e de ensinar a retidão ao país, eu coloquei a verdade (kittum) e a justiça (mīšarum) na boca do país» ${ }^{44}$.

${ }^{40}$ ARM XXVI/2 386, 1. 6'-10'.

${ }^{41}$ O título de «rei do país de Sumer e Akkad» era, de facto, utilizado pelo senhor de toda a região sul da Mesopotâmia. Rîm-Sîn, utilizara-o durante largos anos, até à sua queda às mãos de Hammu-rabi (veja-se RIME 4, 273 e ss).

${ }^{42}$ É o caso de Atamrum, rei do Andarig. Hammu-rabi ter-se-á conseguido impor lentamente região norte, afastando dessa zona os seus concorrentes mais diretos. Veja-se Charpin et Ziegler 2003, 233-34.

${ }^{43}$ As negociações para a conclusão da paz entre a Babilónia e Ešnunna teriam sido adiadas aquando da guerra contra Larsa. Cf. Ibid. 227-28 e 232.

${ }^{44} \mathrm{CH}$, prólogo, V, 1. 5-12 e 14-23. 
Estes dois termos, kittum e mīšarum, traduzem genericamente a ideia de «justiça». Contudo, as palavras provêm de raízes que têm sentidos diferentes e, como tal, exprimem ideias algo distintas.

mīšarum provém de uma raiz que tem o sentido de "(re)ordenar»". Ora, o que Hammu-rabi pretende quando chega ao trono de Larsa é precisamente começar do zero, repor a ordem política e social. Para isso, o soberano decreta um édito (édito-mīšarum) cuja finalidade é a remissão das dívidas económicas e a libertação daqueles que haviam caído na escravidão. Num domínio mais ideológico, o édito pretendia estabelecer um novo começo, restaurar e reforçar a ordem sociopolítica. O propósito da medida era que Hammu-rabi se apresentasse perante os habitantes de Larsa como um rei justo e benevolente ${ }^{46}$.

Todavia, ao contrário do que esta ideia possa levar a crer, a imposição de Hammu-rabi em Larsa não passa por anular as infraestruturas existentes. De facto, num plano mais ligado ao conceito de kittum, de algo que é "permanente», que é «estável» $»^{47}$, Hammu-rabi assegura uma certa continuidade política. Quando chega a Larsa, o monarca afirma-se como se de um natural sucessor de Rîm-Sîn se tratasse. Ao seguir as normas vigentes e possibilitar a manutenção das instituições existentes, Hammu-rabi aproxima-se dos seus cidadãos. Podemos testemunhar este esforço de continuidade num documento enviado por Hammu-rabi ao governador de Larsa: «Investiga o caso deles. Determina a sentença que lhes deve ser aplicada de acordo com as leis que estão em vigor no Yamutbal ${ }^{48}$ ».

Os dois conceitos não se anulam; pelo contrário, eles são complementares. E são ideias como estas que Hammu-rabi põe em prática de modo a anexar Larsa pacificamente e a evitar a eclosão de revoltas. A Babilónia passa então a constituir um território contínuo e unificado. Esta obra centralizadora explica, em grande medida, o sucesso de Hammu-rabi, que, no final do seu governo, se torna senhor de um vasto domínio territorial. A sua hegemonia estendia-se então desde o Golfo Pérsico até à zona do Sindjar. A supremacia alcançada por Hammu-rabi possibilitar-lhe-ia adotar o título de «rei dos quatro cantos do mundo».

${ }^{45}$ Tem um sentido dinâmico, ao contrário de kittum. Veja-se Bottéro 1987, 330-31.

${ }^{46}$ Era uma medida comum no mundo amorita. O próprio Hammu-rabi teria proclamado um mī̌arum depois de ser entronizado na Babilónia.

${ }^{47}$ De acordo com a «lei».

${ }^{48}$ Nome pelo qual era conhecido o antigo reino de Larsa. AbB 13 10, 1. 9-12. 


\section{Bibliografia}

Bonechi, M. 1993. "Conscription à Larsa après la Conquête Babylonienne." MARI 7:129-64.

Bottéro, J. 1987. Mésopotamie. L'écriture, la raison et les dieux. Paris: Éditions Gallimard.

Bouzon, E. 1986. As Cartas de Hammurabi. Petrópolis: Vozes. 1980. O código de Hammurabi. Petrópolis: Vozes.

Charpin, D. 2003. Hammu-rabi de Babylone. Paris: Presses Universitaires de France.

—_ 2000. "Lettres et procès paléo-babyloniens." In Rendre la justice en Mésopotamie, Archives judiciaires du Proche-Orient ancien (IIIe-Ier millénaires avant J.-C)., ed. F. Joannès, 69-111. Saint-Denis, Presses Universitaires de Vincennes.

_ 1999. "Hammu-rabi de Babylone et Mari: nouvelles sources, nouvelles perspectives." In Babylon: Focus mesopotamischer Geschichte, Wiege früher Gelehrsamkeit, Mythos in der Moderne. Colloquien der Deutschen Orient-Gesellschaft 2, ed. J. Renger, 111-30. Saarland: Saarbrücker Druckerei und Verlag.

.1990a. "Les édits de "restauration" des rois babyloniens et leur application." In Du pouvoir dans l'antiquité: mots et réalité, ed. Cl. Nicolet, 13-24. Genève: Librairie Droz.

__ 1990b. "Une alliance contre l'Elam et le rituel du lipit napištim." In Contribution à l'histoire de l'Iran: Mélanges offerts à Jean Perrot, ed. F. Vallat, 109-18. Paris: Éditions Recherche sur les Civilisations.

—_ 1987. "Les décrets royaux à l'époque paléo-babylonienne, à propos d'un ouvrage récent." AfO 34:36-44.

Charpin, D. e J.-M. Durand. 1991. "La suzeraineté de l'empereur (sukkalmah) d'Elam sur la Mesopotamie et le 'nationalisme' a morrite." In Mésopotamie et Elam: Actes de la XXXVIème Rencontre Assyriologique Internationale, (Gand, 10-14 Julho 1989), ed. L. De Meyer e H. Gasche, 59-66. Ghent: University of Ghent.

Charpin, D., F. Joannès, S. Lackenbacher e B. Lafont. 1998. Archives Épistolaires de Mari 1/2 (Archives Royales de Mari XXVI). Paris: Éditions Recherche sur les Civilisations.

Charpin, D. e N. Ziegler, eds. 2003. Mari et le Proche-Orient à l'époque amorrite - Essai d'histoire politique. FM V (Mémoires de N.A.B.U. 6). Paris: Société pour l'étude du Proche-Orient ancien.

Durand, J.-M. 1997-2000. Documents Épistolaires du Palais de Mari, vol. 1-3. LAPO 16-18. Paris: Les Éditions du Cerf. 
1990. "Fourmis blanches et fourmis noires." In Contribuition à l'histoire de l'Iran: Mélanges offerts à Jean Perrot, ed. F. Vallat, 101-8. Paris: Éditions Recherche sur les Civilisations.

Finet, A. 1973. Le Code de Hammurabi. LAPO 6. Paris: Les Éditions du Cerf.

Frayne, D. 1990. Old Babylonian Period (2003-1595 BC), RIME 4. Toronto: University of Toronto Press.

Lacambre, D. 1997. “La Bataille de Hirîtum.” MARI 8:431-54.

Peterson, J. 2016. “The Literary Corpus of the Old Babylonian Larsa Dynasties. New Texts, New Readings, and Commentary.” In Studia Mesopotamica 3, ed. M. Dietrich, K. A. Metzler e H. Neumann. Münster: Ugarit-Verlag.

Sanmartín, J. e J. López. 1993. Mitología y Religión del Oriente Antiguo. Vol. I Egipto-Mesopotamia. Sabadell: Editorial Ausa.

Sasson, J. M. 1995. “King Hammurabi of Babylon.” In Civilizations of the Ancient Near East, ed. J. M. Sasson, 901-15. New York: Scribners.

Mieroop, Van de. 2005. King Hammurabi of Babylon: A Biography. Oxford: Blackwell Publishing.

—. 1993. "The reign of Rim-Sin." RA 87:47-69.

Soldt, W. H. van, ed. 1994. Letters in the British Museum. Part 2: Transliterated and Translated. Altbabylonische Briefe in Umschrift und Übersetzung. Vol. 13. Leiden: Brill. 